\title{
Review of the Methods of Optimization of Irrigation
}

\author{
RAE ZH Aliyev* \\ Director of the Institute of erosion and Irrigation of the Azerbaijan National Academy of Sciences, Azerbaijan
}

Submission: January 04, 2018; Published: January 08, 2018

*Corresponding author: RAE ZH Aliyev, Director of the Institute of erosion and Irrigation of the Azerbaijan National Academy of Sciences, Azerbaijan, Email: zakirakademik@mail.ru

\section{Annotation}

Reviewed the original methods for solving tasks of optimization of irrigation regime by applying dynamic programming theory based integrated Bellman, where the task of operational management of irrigation, solvable in terms of months.

Keywords: The method of dynamic programming; The task of allocating resources; Bellman principle; Optimization of irrigation regime

\section{Overview Methods of Optimization of Irrigation}

It is believed that the anthropogenic transformation of the biosphere in a certain sense has the nature of a global catastrophe and anthropogenic landscape is the landscape of the future. Apparently, in 100-200 years it will occupy the entire territory of the earth's surface with the possible exception of eternal ice and mountain peaks. The reasons for this lie in the uncontrolled and progressive growth of the population of the Earth, in the nonstop expansion of industry and agriculture, in the constant need of man for energy sources, other processes that accompany the «triumph of civilization» [1]. When applying the method of dynamic programming solution to the problem of resource allocation leads to address the functional equation under given constraints Bellman view equalities or inequalities:

$$
\begin{aligned}
& \mathrm{Q} \leq \mathrm{Q}_{\max } \\
& \mathrm{K}(\mathrm{T}) \leq \mathrm{K}_{0}
\end{aligned}
$$

Where $\mathrm{F}$ is maximized functional, in General, income from crop;

(T)-the quality of the harvest;

$\mathrm{To}_{0}$-border quality;

Q-irrigation norm;

$\mathrm{Q}_{\max }$-maximum irrigation norm;

f-function of vegetation.

Bellman principle $[2,3]$ means that regardless of the status of the control object at time $t$ the remaining resources should be spent in an optimal way. Adopted the hypothesis of nonrecoverability crop losses due to lack of moisture. When applying dynamic programming treatment is relatively easy: the limitations it provides to the usual tasks of mathematical programming. When solving particular tasks with dependencies (f) free-form decision usually starts at the end of the specified time interval. While we have a solution on the $t$ step in the solution's features on $t-1$ step and is remembered as the tabulated function of maximum functionality depending on the balance of resources [4]. Then the process continues on t-step 2, etc. When this padding becomes a function of the unknown resource values in the table, and after reaching the beginning of $t=0$ when the initial resource, there is a set of joined tables, using which direct method course: starting with the first step with the building rooms step; because at each step there is a resource used and optimal in this resource before $t$ behavior when transitioning between tables.

Dynamic programming method also allows you to solve problems with the conditions of the crosscutting approach, i.e. with undocked right end with lack of ill harvest time fastening and times change phases of weed $[2,5,6]$. In the application of calculus in the presence of equation (1) for any object is usually solved the problem of optimization of integrated functionality:

$J=\int_{a}^{b} F\left(y, y^{1}, t\right) d t$

which is reduced to the solution of the Euler equations

$\frac{\partial F}{\partial y_{i}}-\frac{d}{d t}\left[\frac{\partial F}{\partial y^{\prime}}\right]=0 \mathrm{i}=1 \ldots . . \mathrm{K}$

where $\mathrm{J}$ is maximised functionality. If there are restrictions of the type equations on integrals can be done using the method of Lagrange multipliers, a task with a constraint on total water $g=\int_{a}^{b} \varphi\left(y, y^{1}, t\right) d t$ (4)

then the Euler equations becomes: 


$$
\frac{\partial F}{\partial y_{i}}-\frac{d}{d t}\left[\lambda+\left(\frac{\partial F}{\partial y_{i}}\right)\right]=0 \mathrm{i}=1_{2 \ldots . . m}
$$

where $\lambda$ is the Lagrange multiplier; $m$ is the number of constraints.

When constraints types: $g(t)=\left(y, y^{1}, t\right)$

the Lagrange multiplier $\lambda$ is replaced by Lagrange function $\lambda(t)$ and the equations of the form:

$$
\frac{\partial F}{\partial y_{i}}-\frac{d}{d t}\left[\lambda(t)+\left(\frac{\partial F}{\partial y_{i}}\right)\right]=0 \mathrm{i}=1, \ldots \mathrm{m}
$$

When limitations common type inequality for value (i) task is quite difficult, because one has to resort to non-linear change of the conditions, something that makes it very difficult primary challenge. A kind of variation is the task of the Bolza problem with cutting conditions and that add additional terms into the system through a floating right side-lack of fixing the time of harvest and the time change vegetative phases $[1,3,7]$. When you use the maximum, principle for finding the extremum of the integral functional (F) needed to be addressed in a major (3) and (4) of coupled differential equations, minimizing the Hamiltonian h:

$H=F+\sum_{i=1}^{n} \psi_{i} \cdot f$

Where $\psi_{(i)}$-solution of the coupled system and $\psi_{0}=$ F optimality criterion

$$
\frac{d \psi_{i}}{d t}=-\frac{\partial H}{\partial y_{i}}
$$

under the terms of the task $\mathrm{i}_{(\mathrm{i})}(0)=\mathrm{C}_{(\mathrm{i})}$.

In General, the task is a peer-to-peer with boundary conditions it must be satisfying conditions at two points.

In the systems of differential equations increases twice, because faced with the primary and associated tasks. However, dealing with the limitations of both types of equations and inequalities, type here is relatively easier than in variational calculus. Task variation in any of the mentioned options can be resolved on the basis of the knowledge base by using artificial intelligence expert systems assessments. It is helpful to apply hybrid systems, partly using conventional methods of optimization and modeling. The use of artificial intelligence in the form of the hybrid system allows you to replace, to a large extent, the task of identifying knowledge gained in the process of research and industrial-economic activities.

Thus, proceeding from the complexities of working with constraints, it is necessary to abandon the use of calculus. It is obvious that, despite the need for double passage, dynamic programming is quite acceptable for the problem of optimization of crop irrigation regime. In addition to these, there are common techniques enough private methods adapt to optimize the moisture of crops, such as based on the theory of statistical decisions matrix constructed taking losses $[1,6,8,9]$. In the work of the task of selecting the irrigation regime on the basis of climate, regulatory and statistical models for rainfall forecast, taking into account forecasting accuracy is accepted one of three strategies:

$\mathrm{S}_{\mathrm{KL}}$-climatic,

Sn -normative (based on established standards),

$\mathrm{S}_{\mathrm{p}}$-forecast (based on statistical data processing and of methods of regression analysis),

Swholesale -optimal.

Task definition $S_{K L}, S_{n}, S_{p}$ solved in the context of the plan for the year based on years of historical data on crop yields, precipitation, solar radiation, etc. There's also task of operational management of irrigation, solvable in terms of months. It does not, however, examines the current State plants, forecast meteorological conditions, soil moisture and the effect of fertilizing. To address the operational challenges are encouraged to use the method of dynamic programming. Thus, the most natural and practical way to solve the tasks of optimization of irrigation regime is dynamic programming method adapted to the respective conditions of agriculture

\section{References}

1. Protasov IN Maxima and minima in geometry. Library of mathematical education, Russia p. 31.

2. Aliev ZH, Jafarov AM (2007) Use of the method of the Dynamic Programming in process of optimization of the irrigation agriculture in condition of mountain agriculture. The Ninth International Congress of Baku «Emerge, Ecology, Economy", Azerbaijan Republic p. 7-9.

3. Zakir Aliev (2005) Question to protect soil in Azerbaijan republic husbandries. Journal of water and land development, the Institute for Land Reclamation and Environmental Engineering in A Agriculture, Polish academy of Sciences 9: 116-121.

4. (2002) International Center $C / X$ Research in the dry in the Dry Areas (ICARDA) Irrigation regime and monitoring equipment. U Umarova, A Karimov Taraz (edn): IC «AQUA, pp. 128.

5. L Landau, E Lifshitz EM (1986) Hydrodynamics-M, Theoretical physics, vol 6.

6. VS Nosenko (1981) Irrigation in the mountains. Publishing House «Kolos», Russia pp. 143.

7. Falkovich G (2011) Fluid Mechanics (A short course for physicists), Cambridge University Press.

8. Zorich VA (1997) Mathematical analysis. Part 1 ( $2^{\text {nd }}$ Edn)-e CRIN and extra M: PHASIS.

9. Piskunov HC (1985) Differential and integral calculus to technical institutions: A manual for technical institutions. ( $13^{\text {th }}$ edn): Nauka, Home revision physico-mathematical literature, Russia 2: 46-48. 
Your next submission with Juniper Publishers will reach you the below assets

- Quality Editorial service

- Swift Peer Review

- Reprints availability

- E-prints Service

- Manuscript Podcast for convenient understanding

- Global attainment for your research

- Manuscript accessibility in different formats

( Pdf, E-pub, Full Text, Audio)

- Unceasing customer service

Track the below URL for one-step submission https://juniperpublishers.com/online-submission.php 